\title{
Effect of Ni, Mo and Mn content on spinodal decomposition kinetics and G- phase precipitation of aged model cast austenitic stainless steels.
}

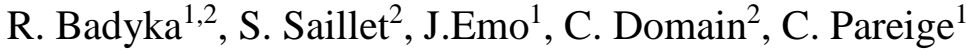 \\ 1. Groupe de Physique des Matériaux, UMR 6634 CNRS, Université de Rouen Normandie et INSA de Rouen Normandie, \\ France, Avenue de l'université, 76801 St Etienne du Rouvray - France
}

2. EDF Lab Les Renardières, MMC Department, F-77250 Moret sur Loing, France

\section{Corresponding Author: cristelle.pareige@ univ-rouen.fr}

Keywords: kinetics, Atom probe tomography, Spinodal decomposition, G-phase precipitation, models alloys

\section{Abstract}

During ageing, the ferritic phase of Cast Austenitic Stainless Steels (CASS) undergoes decomposition by spinodal decomposition and G-phase precipitation, which leads to increasing hardness and decreasing impact toughness. Mo-bearing steels are more prone to ageing than Mo-free steels. To study the effects of Ni, Mo, and Mn, duplex model alloys were thermally aged at 350 and $400^{\circ} \mathrm{C}$. The microstructure evolution during ageing was characterized by atom probe tomography. Only $\mathrm{Ni}$ additions seem to affect the spinodal decomposition kinetics. $\mathrm{Ni}$ accelerates the spinodal decomposition kinetics regardless of the presence of Mo or Mn. Additions of Mo and Mn promote the precipitation of G-phase.

\section{Introduction}

The cast austenitic stainless steels (CASS) are used for components of the primary cooling system of Light Water Reactors (LWR). At service temperature $\left(285^{\circ} \mathrm{C}-323^{\circ} \mathrm{C}\right)$, the CASS toughness decreases and the hardness increases with ageing time due to phase transformations occurring in the ferrite phase. The ferrite decomposes during ageing time into three phases: $\alpha$ (Fe rich) and $\alpha^{\prime}(\mathrm{Cr}$ rich) phases via spinodal decomposition and G-phase via precipitation at $\alpha / \alpha^{\prime}$ interfaces [1-4]. Mo-bearing steels, which also present a higher Ni content, are more prone to ageing than Mo-free steels due to:

- An enhanced spinodal decomposition kinetics [5-8]. The spinodal decomposition kinetics is generally described by power law $\left(\lambda=a t^{b}\right)$ with $b$, the effective time exponent, $\lambda$, the wavelength of the decomposition and t, the ageing time. Danoix et al. [9] and Pareige et al. $[5,10]$ reported an effective time exponent of spinodal decomposition kinetics equal to 0.16 for 
Mo-bearing steels thermally aged up to 20 years at $350{ }^{\circ} \mathrm{C}$ and equal to 0.07 for Mo-free steel thermally aged up to 10 years at the same temperature.

- A higher ( 10 times) number density of G-phase particles [3,5-7,10,11] due to a higher concentration in $\mathrm{Ni}, \mathrm{Si}, \mathrm{Mn}$ and Mo elements (named hereafter G-forming element as they promote the formation of the G-phase).

$\mathrm{Ni}$ has been shown to promote the spinodal decomposition kinetics in FeCrNi alloys [2,12-14] by modifying the pre-exponential term related to the thermodynamics, but not the effective time exponent. Thus, according to these results, the difference in effective time exponent cannot be assigned to the difference in Ni concentration between Mo-bearing and Mo-free steels. Effect of Mo is still not clear. Courtnall and Pickering [15] concluded from hardening measurements that additions of $0.96 \mathrm{wt} \%$ of Mo accelerates the kinetics of spinodal decomposition in $\mathrm{Fe}-\mathrm{Cr}$ Mo alloys. Conversely, Solomon and Levinson [2] showed via Mössbauer spectroscopy analysis in both ternary $\mathrm{Fe}-\mathrm{Cr}-\mathrm{Ni}$ and quaternary $\mathrm{Fe}-\mathrm{Cr}-\mathrm{Ni}-\mathrm{Mo}$ ferritic alloys aged at $475^{\circ} \mathrm{C}$ that Mo did not influenced the kinetics of spinodal decomposition for Mo content less than 3 $\mathrm{wt} \%$. The effect of Mn on spinodal decomposition has also been investigated in a Fe-20 wt.\% Cr-4.5wt.\%Mn ternary ferritic alloy [14]. Mn has been shown to enhance the spinodal decomposition kinetics for this Mn concentration. Nevertheless, the study undertaken by Solomon and Levinson [2] at lower Mn content ( $\approx 0.7$ at $\%$ - close to values of Mo-bearing and Mo-free steels investigated in the present work) did not evidence any effect.

Depending on the composition of the austenitic-ferritic stainless steels, the number density and volume fraction of G-phase are different [5-8]. Shiao et al. [16], Miller and Bentley [17] and Danoix et al. [18] showed that Ni strongly promotes the formation of the G-phase. As for spinodal decomposition, the role of Mo on the G-phase precipitation is still under debate. According to Danoix et al. [18] Mo has no influence on G-phase precipitation in CF8 and CF8M steels. Particles only get richer in Mo at long ageing times (typically after $30,000 \mathrm{~h}$ at $350{ }^{\circ} \mathrm{C}$ ). Conversely, Hamaoka et al. [19] who investigated CF3M and CF3 steels (aged at $450{ }^{\circ} \mathrm{C}$ from $10 \mathrm{~h}$ to 2,000 h) by Transmission Electron Microscopy (TEM) reported that Mo forms nanodomains which would act as precursors of G-phase particles. Regarding $\mathrm{Mn}$, to our knowledge, no study has been performed on its possible influence on G-phase precipitation.

To prevent degradation of the mechanical properties of CASS, it is important to understand the role of the alloying elements on the kinetics of the ferrite decomposition. In this study the effect of Ni, Mo and Mn on both spinodal decomposition and G-phase precipitation was carried by Atom Probe Tomography (APT) on austenitic-ferritic model alloys thermally aged at $350{ }^{\circ} \mathrm{C}$ and $400{ }^{\circ} \mathrm{C}$. After presentation of the different materials studied (composition and heat 
treatment) and the experimental techniques, the results obtained will be presented and compared with results obtained for industrial steels.

\section{a. Materials}

The model alloys were cast by OCAS in an induction vacuum furnace. They were heat treated at $1,100{ }^{\circ} \mathrm{C}$ for $6 \mathrm{~h}$ to fix the ferrite content. This temperature is similar to the one used for CASS (around $1,100^{\circ} \mathrm{C}$ ). The composition, ageing treatment and calculated volume fraction of ferrite are provided in Table 1 for these model alloys and reference industrial alloys (A, B and C). The ferrite compositions are given in Table 2. The volume fraction of ferrite was calculated using the alloy composition and the formula proposed by Bonnet et al. [20].

Table 1: Bulk composition (wt \%), calculated volume fraction of ferrite $(\delta(\%))$, and intervals of ageing times and temperatures of the studied steels.

\begin{tabular}{|c|c|c|c|c|c|c|c|c|c|c|}
\hline Alloy (wt $\%)$ & $\mathrm{Cr}$ & $\mathrm{Ni}$ & $\mathrm{Si}$ & Mo & Mn & $\mathrm{C}$ & $\mathrm{Fe}$ & $\delta(\%)$ & Ageing time $(\mathrm{h})$ & $\begin{array}{c}\text { Ageing } \\
\text { temperature }\left({ }^{\circ} \mathrm{C}\right)\end{array}$ \\
\hline A-350 [10] & 21.0 & 9.8 & 1.1 & 2.7 & 0.7 & 0.03 & Bal. & 29.5 & \multirow{3}{*}{$\begin{array}{c}2,500 ; 10,000 \\
30,000 \text { and } \\
100,000\end{array}$} & \multirow{3}{*}{350} \\
\hline B-350 [10] & 20.1 & 11.7 & 1.1 & 2.5 & 0.8 & 0.03 & Bal. & 17 & & \\
\hline $\mathrm{C}-350[5]$ & 20.3 & 8.4 & 0.9 & 0.04 & 0.8 & 0.03 & Bal. & 12 & & \\
\hline $8 \mathrm{NiSi}$ & 21.1 & 8.0 & 0.9 & 0.01 & Traces & 0.03 & Bal. & 30.7 & \multirow{6}{*}{$\begin{array}{c}1,000 ; 2,500 ; \\
10,000 \text { and } 30,000 \\
\text { And } \\
500 ; 1,000 ; 5,000 \\
\text { and } 10,000\end{array}$} & \multirow{6}{*}{$\begin{array}{l}350 \\
\text { And } \\
400\end{array}$} \\
\hline 8NiSiMo & 21.0 & 7.9 & 1 & 2.3 & Traces & 0.03 & Bal. & 77.1 & & \\
\hline $10 \mathrm{NiSi}$ & 21.0 & 10.4 & 1.1 & 0.01 & Traces & 0.04 & Bal. & 11.2 & & \\
\hline 10NiSiMo & 20.9 & 10.4 & 1.0 & 2.5 & Traces & 0.04 & Bal. & 27.8 & & \\
\hline 10NiSiMn & 21.1 & 10.8 & 1.0 & 0 & 0.8 & 0.03 & Bal. & 9.0 & & \\
\hline 10NiSiMnMo & 20.4 & 10.5 & 1.0 & 2.4 & 0.8 & 0.03 & Bal. & 22.4 & & \\
\hline
\end{tabular}


Table 2: Ferrite composition (at \%). Traces of $\mathrm{Cu}, \mathrm{P}$ and $\mathrm{V}$ are also detected at levels below 0.02 at $\%$ obtained by atom probe tomography data. The error indicated is equal to three standard deviation.

\begin{tabular}{|c|c|c|c|c|c|c|c|}
\hline Alloy (\%at.) & $\mathrm{Ni}$ & $\mathrm{Si}$ & $\mathrm{Mo}$ & $\mathrm{Mn}$ & $\mathrm{C}$ & $\mathrm{Cr}$ & $\mathrm{Fe}$ \\
\hline A-350 [10] & $5.42 \pm 0.06$ & $2.59 \pm 0.04$ & $2.09 \pm 0.04$ & $0.54 \pm 0.02$ & Trace & $27.38 \pm 0.12$ & Bal. \\
\hline B-350 [10] & $5.48 \pm 0.06$ & $2.62 \pm 0.04$ & $2.57 \pm 0.04$ & $0.70 \pm 0.02$ & $0.02 \pm 0.01$ & $27.51 \pm 0.11$ & Bal. \\
\hline $\mathrm{C}-350[5]$ & $3.51 \pm 0.97$ & $2.56 \pm 0.02$ & $0.03 \pm 0.01$ & $0.21 \pm 0.01$ & Traces & $26.11 \pm 0.12$ & Bal. \\
\hline $8 \mathrm{NiSi}$ & $4.69 \pm 0.01$ & $2.41 \pm 0.01$ & Trace & Trace & Traces & $26.02 \pm 0.02$ & Bal. \\
\hline $8 \mathrm{NiSiMo}$ & $4.95 \pm 0.01$ & $2.23 \pm 0.01$ & $1.85 \pm 0.01$ & $0.01 \pm 0.01$ & $0.01 \pm 0.01$ & $25.41 \pm 0.02$ & Bal. \\
\hline $10 \mathrm{NiSi}$ & $5.67 \pm 0.01$ & $2.28 \pm 0.01$ & $0.01 \pm 0.01$ & $0.02 \pm 0.01$ & $0.02 \pm 0.01$ & $27.01 \pm 0.01$ & Bal. \\
\hline $10 \mathrm{NiSiMo}$ & $6.39 \pm 0.01$ & $2.23 \pm 0.01$ & $2.08 \pm 0.01$ & $0.01 \pm 0.01$ & $0.01 \pm 0.01$ & $25.32 \pm 0.01$ & Bal. \\
\hline $10 \mathrm{NiSiMn}$ & $5.96 \pm 0.01$ & $2.41 \pm 0.01$ & Traces & $0.64 \pm 0.01$ & $0.05 \pm 0.01$ & $27.76 \pm 0.01$ & Bal. \\
\hline $10 \mathrm{NiSiMnMo}$ & $6.32 \pm 0.01$ & $2.27 \pm 0.01$ & $2.13 \pm 0.01$ & $0.59 \pm 0.01$ & $0.01 \pm 0.01$ & $24.96 \pm 0.01$ & Bal. \\
\hline
\end{tabular}

\section{b. Experimental Methods}

\section{Microstructural characterization}

APT analyses of the ferrite of the alloys were conducted using a high-resolution local electrode atom probe, LEAP $4000 \mathrm{HR}$ (CAMECA) with a detector efficiency of $36 \%$. During experiments, specimens were cooled down to $40-50 \mathrm{~K}$ in order to avoid preferential field evaporation of chromium. Atoms were evaporated by applying an electric pulse of $20 \%$ of the DC voltage with a pulse repetition rate of $200 \mathrm{kHz}$ and with a detection rate equal to $0.3 \%$. The basic principle of APT technique may be found in different books or articles [21-23]. APT samples were prepared either by focus ion beam (FIB) or by standard electro polishing methods. 3D reconstructions were performed using IVAS software (CAMECA) and the data were analysed using the three-dimensional data software for atom probe users developed by GPM, Rouen, France. For reconstruction, an image compression factor equal to 1.5 and a field factor value ranging between 3.6 and 5 (depending of the analysed sample and on the fact that samples were on microcoupon or not) were used. Field factor values were adjusted so as interplanar distances corresponding to the detected crystallographic directions are correct for each experiment.

Characterization of the microstructure has been performed with the same parameters as in [3]. Spinodal decomposition is characterized by its wavelength $(\lambda)$ and amplitude. The mean wavelength of the spinodal decomposition was estimated using autocorrelation functions calculated from 1D Cr concentration profiles [24]. The profiles were drawn by extracting 
volumes of square cross section of $1 \times 1 \mathrm{~nm}^{2}$ from the whole analysed volume and by moving a $1 \times 1 \times 1 \mathrm{~nm}^{3}$ box along the $\mathrm{z}$ axis with a step value of $0.1 \mathrm{~nm}$. The mean wavelengths have been calculated over at least 50 concentration profiles for each APT volume and from at least two different tips for each condition. The wavelengths were derived from the first two peaks of each auto-correlation profile. The uncertainty on the wavelengths is equal to two times the standard deviation calculated over more than 300 values of wavelength per condition. The amplitude of the spinodal decomposition is defined by $\Delta C r=C_{C r \alpha \prime}-C_{C r \alpha}$, where $C_{C r \alpha \prime}$ and $C_{C r \alpha}$ are the Cr concentration in $\alpha^{\prime}$ and $\alpha$ zones respectively. Composition of $\alpha^{\prime}$ and $\alpha$ zones has been derived using the method proposed by Zhou et al. [25]. Regarding G-phase precipitation, the radius of the particles and the number density were calculated for each analysis. A concentration filter $[5,22,26]$ was applied to isolate G-phase particles from $\alpha$ and $\alpha^{\prime}$ regions using the concentration threshold $\mathrm{X}_{\mathrm{Ni}+\mathrm{Si}+\mathrm{Mn}+\mathrm{Mo}}>15 \%$. The threshold corresponds to the value for which the concentration histogram of the randomized data set of same composition is negligible $(<0.01 \%)$ [27]. As a consequence of the filtering procedure, Fe shells are sometimes observed around particles. These shells were removed using an erosion method. Once the Fe shells were removed, the particle Guinier radius $\left(\mathrm{R}_{\mathrm{G}}\right)$ of each individual particle was calculated. For more information on the atom-probe characterization procedure, refer to Lefebvre et al. [22]. The number density of the G-phase particles was determined by the ratio of the number of the observed precipitates to the overall analyzed volume. The in-core composition of the G-phase particles is obtained from the plateau observed on the erosion profiles i.e. the interface is not considered in the calculation of the particle's composition guarantying the true composition of the particles to be considered. It is worth noting that G-phase particles observed at $350{ }^{\circ} \mathrm{C}$ did not show any field contrast with the surrounding $\alpha$ and $\alpha^{\prime}$ zones i.e. there are no trajectory aberrations which could impact composition measurements. At $400{ }^{\circ} \mathrm{C}$, for more concentrated particles, a small evaporation field contrast appears revealing that G-phase particles have a slightly higher evaporation field than $\alpha$ and $\alpha^{\prime}$ zones. In such a case, no matrix atoms enter the precipitates and trajectory overlaps are expected to only impact interfaces [28-30]. 


\section{Results}

a. Metallography

The optical micrographs of each unaged model alloy and the duplex stainless steel A-350 obtained after polishing and sodium hydroxide attack are given in Figure 1.
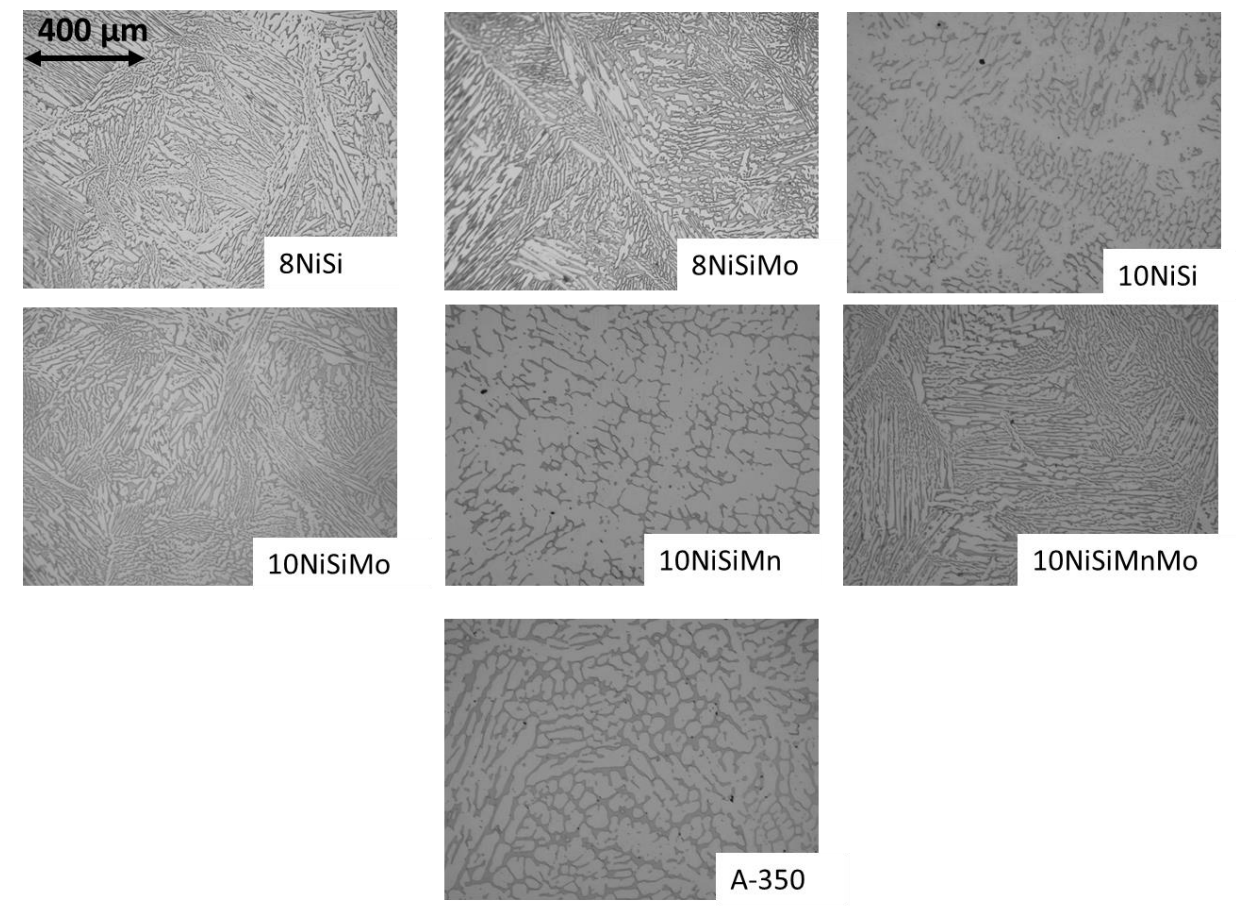

Figure 1: Optical micrographs of model alloys and A-350 steel at unaged condition. Ferrite in dark, austenite in grey.

A duplex structure with ferrite in dark and austenite in light grey is observed for all alloys. In agreement with alloys' composition and ferrite content, the $8 \mathrm{NiSiMo} \mathrm{contains} \mathrm{more} \mathrm{ferrite} \mathrm{than}$ the other alloys. Size of ferritic domains is larger in the industrial A-350 alloy, than in model alloys even in the case of the $10 \mathrm{NiSiMnMo}$ whose composition is very close to A-350 one. Differences in solidification rates may explain this observation.

\section{b. Atom probe characterization}

Table 3 presents the conditions investigated by APT. Between 2 and 4 APT samples were analysed per ageing condition. 
Table 3 : Thermal ageing conditions of the model alloys analysed by APT.

\begin{tabular}{|c|c|c|}
\hline \multirow{2}{*}{ Alloys } & \multicolumn{2}{|c|}{ Thermal ageing conditions } \\
\cline { 2 - 3 } & $\mathbf{3 5 0}{ }^{\circ} \mathbf{C}$ & $\mathbf{4 0 0}{ }^{\circ} \mathrm{C}$ \\
\hline $8 \mathrm{NiSi}$ & $1,000 \mathrm{~h}$ and $2,500 \mathrm{~h}$ & No data \\
\hline $8 \mathrm{NiSiMo}$ & $1,000 \mathrm{~h} ; 2,500 \mathrm{~h}$ and $30,000 \mathrm{~h}$ & $500 \mathrm{~h}$ and $1,000 \mathrm{~h}$ \\
\hline $10 \mathrm{NiSi}$ & $2,500 \mathrm{~h}$ and $10,000 \mathrm{~h}$ & $500 \mathrm{~h} ; 1,000 \mathrm{~h} ; 5,000 \mathrm{~h}$ and \\
& & $500 \mathrm{~h} ; 1,000 \mathrm{~h} ; 5,000 \mathrm{~h}$ and \\
\hline $10 \mathrm{NiSiMo}$ & $1,000 \mathrm{~h} ; 2,500 \mathrm{~h} ; 10,000 \mathrm{~h}$ and & $5000 \mathrm{~h}$ \\
\hline $10 \mathrm{NiSiMn}$ & $30,000 \mathrm{~h}$ & $500 \mathrm{~h}$ and $5,000 \mathrm{~h}$ \\
\hline $10 \mathrm{NiSiMnMo}$ & $2,500 \mathrm{~h}$ and $10,000 \mathrm{~h}$ & $500 \mathrm{~h}$ and $5,000 \mathrm{~h}$ \\
\hline
\end{tabular}

Figure 2 and Figure 4 show the $\mathrm{Cr}$ distribution (red) and $\mathrm{Ni}+\mathrm{Si}+\mathrm{Mo}+\mathrm{Mn}$ distribution (green) in $3 \mathrm{D}$ volumes obtained by APT for model alloys aged at $350{ }^{\circ} \mathrm{C}$ and $400{ }^{\circ} \mathrm{C}$ respectively. Figure 3 shows the distribution of $\mathrm{Ni}+\mathrm{Si}+\mathrm{Mo}$ elements in $10 \mathrm{NiSiMo}$ thermally aged $30,000 \mathrm{~h}$ at $350{ }^{\circ} \mathrm{C}$. Figure 5 presents the distribution of $\mathrm{Ni}+\mathrm{Si}+\mathrm{Mo}+\mathrm{Mn}$ atoms for $10 \mathrm{NiSiMo}, 10 \mathrm{NiSiMn}$ and $10 \mathrm{NiSiMnMo}$ alloys aged at $400{ }^{\circ} \mathrm{C}$. $8 \mathrm{NiSi}$ alloy is not presented as its microstructure is the same as $8 \mathrm{NiSiMo}$ one.

Spinodal decomposition is observed for all alloys at $350{ }^{\circ} \mathrm{C}$ and $400{ }^{\circ} \mathrm{C}$. Regarding G-phase particles, three behaviours are revealed: no G-phase particles, G-phase particles at the $\alpha / \alpha^{\prime}$ interfaces (e.g. $2,500 \mathrm{~h}$ at $350{ }^{\circ} \mathrm{C}$ in $10 \mathrm{NiSiMnMo}$ ) and G-phase particles along dislocations lines only (e.g. $10,000 \mathrm{~h}$ at $350{ }^{\circ} \mathrm{C}$ in $10 \mathrm{NiSiMo}$ ). Because G-phase particles nucleate at $\alpha / \alpha^{\prime}$ due to cross flow of $\mathrm{Ni}$ and $\mathrm{Si}$ between $\alpha$ - Fe rich zones and $\alpha^{\prime}-\mathrm{Cr}$ rich zones [31-33] and grow and coarsen via vacancy diffusion along the $\alpha / \alpha$ ' interfaces [32], they are named "G-phase particles at the $\alpha / \alpha^{\prime}$ interface" in the following. When the number density is low and alignment along dislocation lines of G-phase particles not obvious, it is difficult to distinguish G-phase particles formed at $\alpha / \alpha^{\prime}$ interfaces from G-phase particles formed at dislocation lines as for example in $10 \mathrm{NiSiMo}$ alloy at $350{ }^{\circ} \mathrm{C}$ (Figure 3). In this case, it has been considered that the particles are formed at the $\alpha / \alpha^{\prime}$ interfaces. 


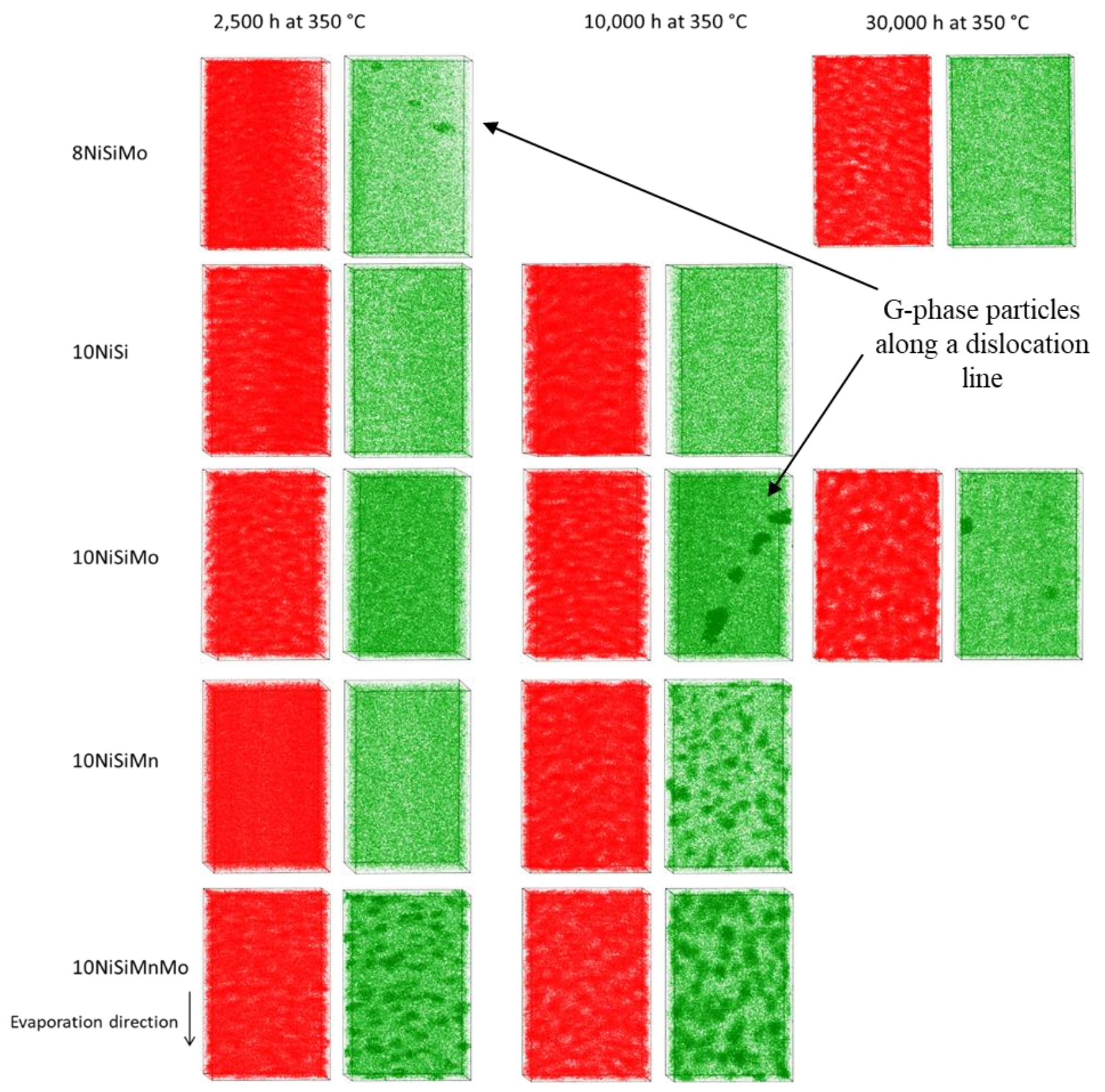

Figure 2: Distribution of $\mathrm{Cr}$ atoms (in red) and $\mathrm{Ni}+\mathrm{Si}+\mathrm{Mo}+\mathrm{Mn}$ atoms (in green) after ageing of 2,500 $\mathrm{h}$, $10,000 \mathrm{~h}$ and $30,000 \mathrm{~h}$ at $350{ }^{\circ} \mathrm{C}$ for $8 \mathrm{NiSiMo}$, 10NiSi, 10NiSiMo, 10NiSiMn and 10NiSiMnMo. Volume $=30 \times 30 \times 50 \mathrm{~nm}^{3} \cdot($ Color online $)$ 


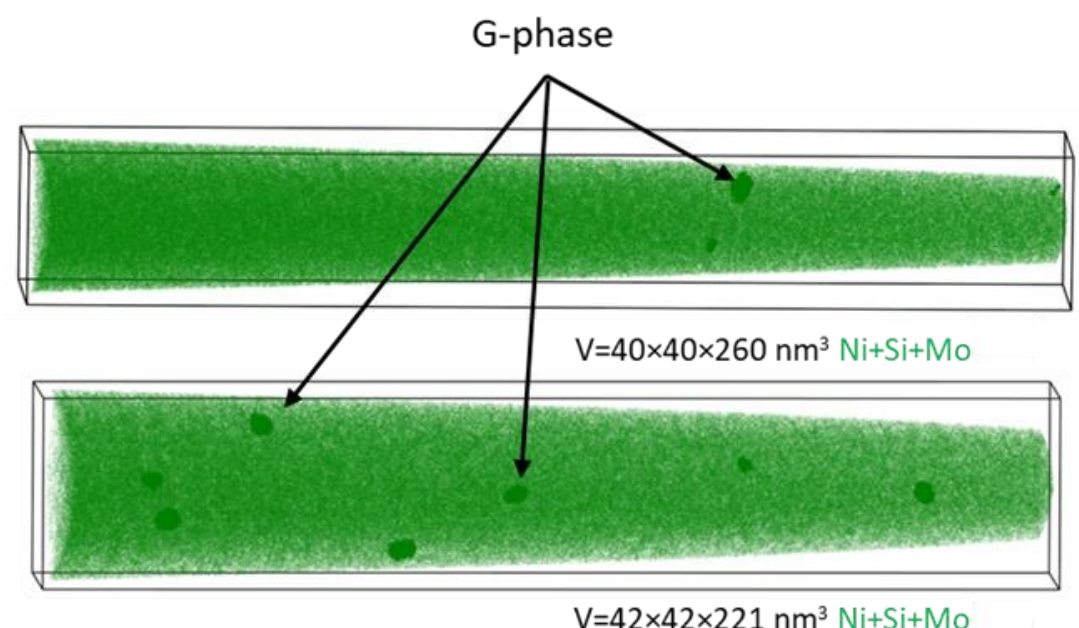

Figure 3: $\mathrm{Ni}+\mathrm{Si}+\mathrm{Mo}$ atoms distribution for different volumes of $10 \mathrm{NiSiMo}$ aged $30,000 \mathrm{~h}$ at $350{ }^{\circ} \mathrm{C}$. (Color online)

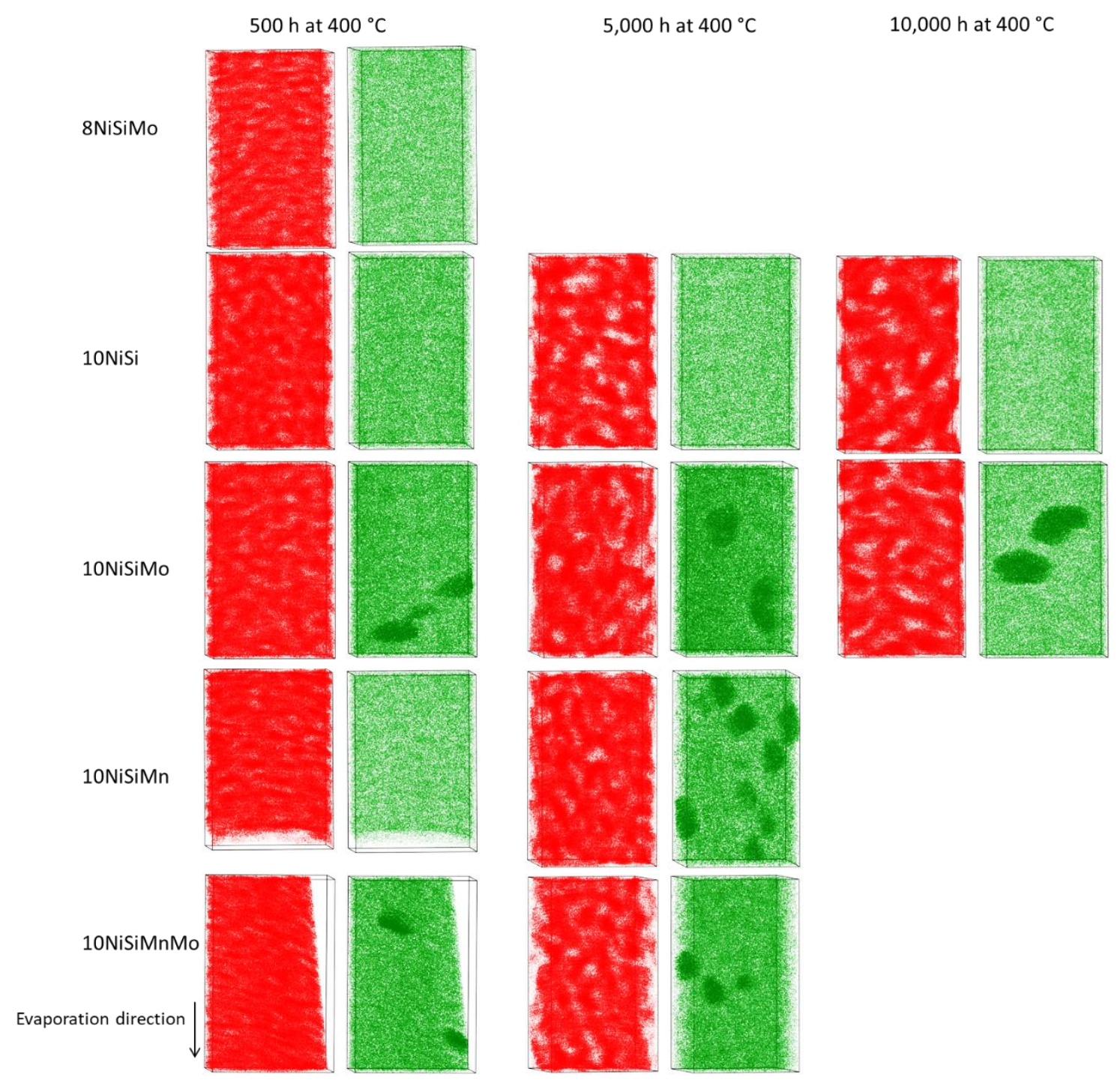

Figure 4: Distribution of $\mathrm{Cr}$ atoms (in red) and $\mathrm{Ni}+\mathrm{Si}+\mathrm{Mo}+\mathrm{Mn}$ atoms (in green) after ageing of $500 \mathrm{~h}$, $5,000 \mathrm{~h}$ and $10,000 \mathrm{~h}$ at $400{ }^{\circ} \mathrm{C}$ for $8 \mathrm{NiSiMo}$, 10NiSi, 10NiSiMo, 10NiSiMn and 10NiSiMnMo. Volume $=30 \times 30 \times 50 \mathrm{~nm}^{3} . \mathrm{V}=30 \times 30 \times 43 \mathrm{~nm}^{3}$. (Color online $)$ 
a)

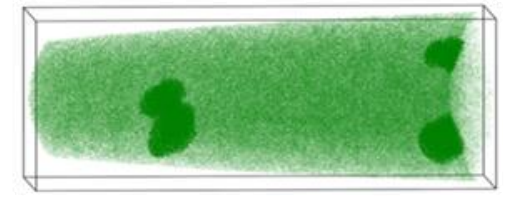

$V=46 \times 46 \times 108 \mathrm{~nm}^{3}$

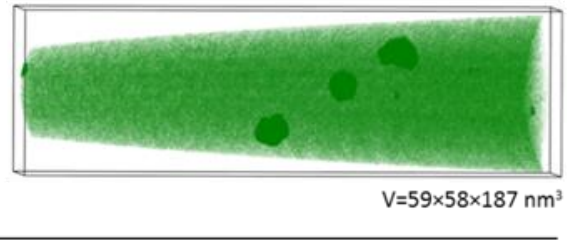

b)

10NiSiMo $10000 \mathrm{~h}$

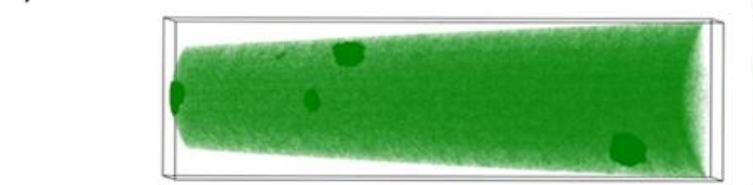

$V=68 \times 67 \times 208 \mathrm{~nm}^{3}$

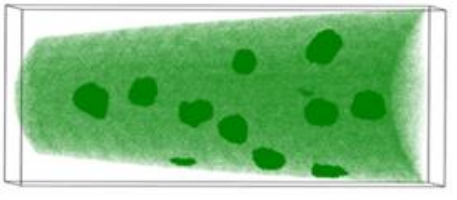

$\mathrm{V}=77 \times 79 \times 133 \mathrm{~nm}^{3}$

c)

10NiSiMn $5000 \mathrm{~h}$

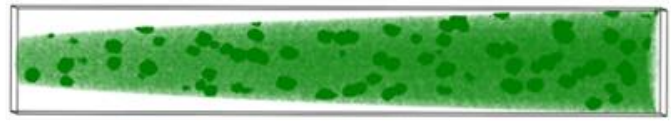

$V=56 \times 56 \times 328 \mathrm{~nm}^{3}$ $\mathrm{V}=56 \times 56 \times 346 \mathrm{~nm}^{3}$

10NiSiMnMo $5000 \mathrm{~h}$

d)
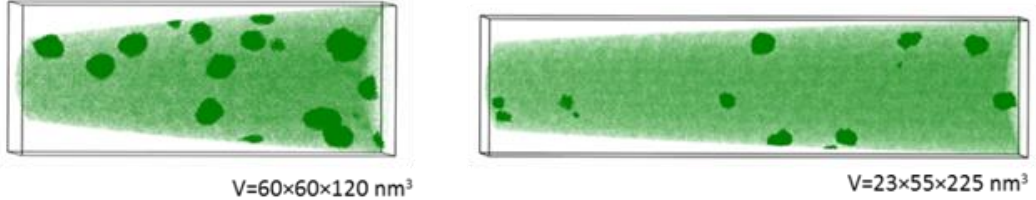

Figure 5: $\mathrm{Ni}+\mathrm{Si}+\mathrm{Mo}+\mathrm{Mn}$ atoms distribution for different APT volumes for (a) 10NiSiMo aged 5,000 h, (b) 10NiSiMo aged 10,000 h, (c) 10NiSiMn aged 5,000 h and (d) 10NiSiMnMo aged 5,000 h at $400{ }^{\circ} \mathrm{C}$. (Color online)

After ageing at $350{ }^{\circ} \mathrm{C}$, two groups have been identified based on the atom distributions presented in figures 4 to 6 :

- In the first group of alloys, the ferrite decomposed into $\alpha$ and $\alpha^{\prime}$ zones and G-phase particles at the $\alpha / \alpha^{\prime}$ interfaces. This group concerns $10 \mathrm{NiSiMo,} 10 \mathrm{NiSiMn}$ and $10 \mathrm{NiSiMnMo}$ alloys. It is interesting to note, however, that for some conditions, Gphase precipitation presents a kinetic delay: 2,500 h at $350{ }^{\circ} \mathrm{C}$ for $10 \mathrm{NiSiMn}$ and $30,000 \mathrm{~h}$ at $350{ }^{\circ} \mathrm{C}$ for $10 \mathrm{NiSiMo}$. Moreover, surprisingly, 10NiSiMn also shows a kinetic delay of 2,500 $\mathrm{h}$ for spinodal decomposition whereas spinodal decomposition is a second order reaction.

- In the second group of alloys (8NiSi, $8 \mathrm{NiSiMo}$ and $10 \mathrm{NiSi}$ ), only spinodal decomposition is observed. In some cases, G-phase particles at dislocation lines are detected. 
After ageing at $400{ }^{\circ} \mathrm{C}$, the same groups are observed: 10NiSiMo, 10NiSiMn, 10NiSiMnMo, the first group on one hand, and $8 \mathrm{NiSi}, 8 \mathrm{NiSiMo}$ and $10 \mathrm{NiSi}$, the second group on the other hand. For the first group, at this temperature, G-phase particles are observed only after 5,000 h. It must be emphasised that G-phase particle distribution between APT volumes of a same alloy is more heterogeneous at $400{ }^{\circ} \mathrm{C}$ than at $350{ }^{\circ} \mathrm{C}$ (Figure 5).

\section{Spinodal decomposition characterisation:}

Figure 6 reports, (a) the evolution of the wavelength and (b) the amplitude of $\mathrm{Cr}$ concentration fluctuations of the spinodal decomposition for model alloys aged at $350{ }^{\circ} \mathrm{C}$. Same graphs for model alloys aged at $400{ }^{\circ} \mathrm{C}$ are presented in Figure 7.
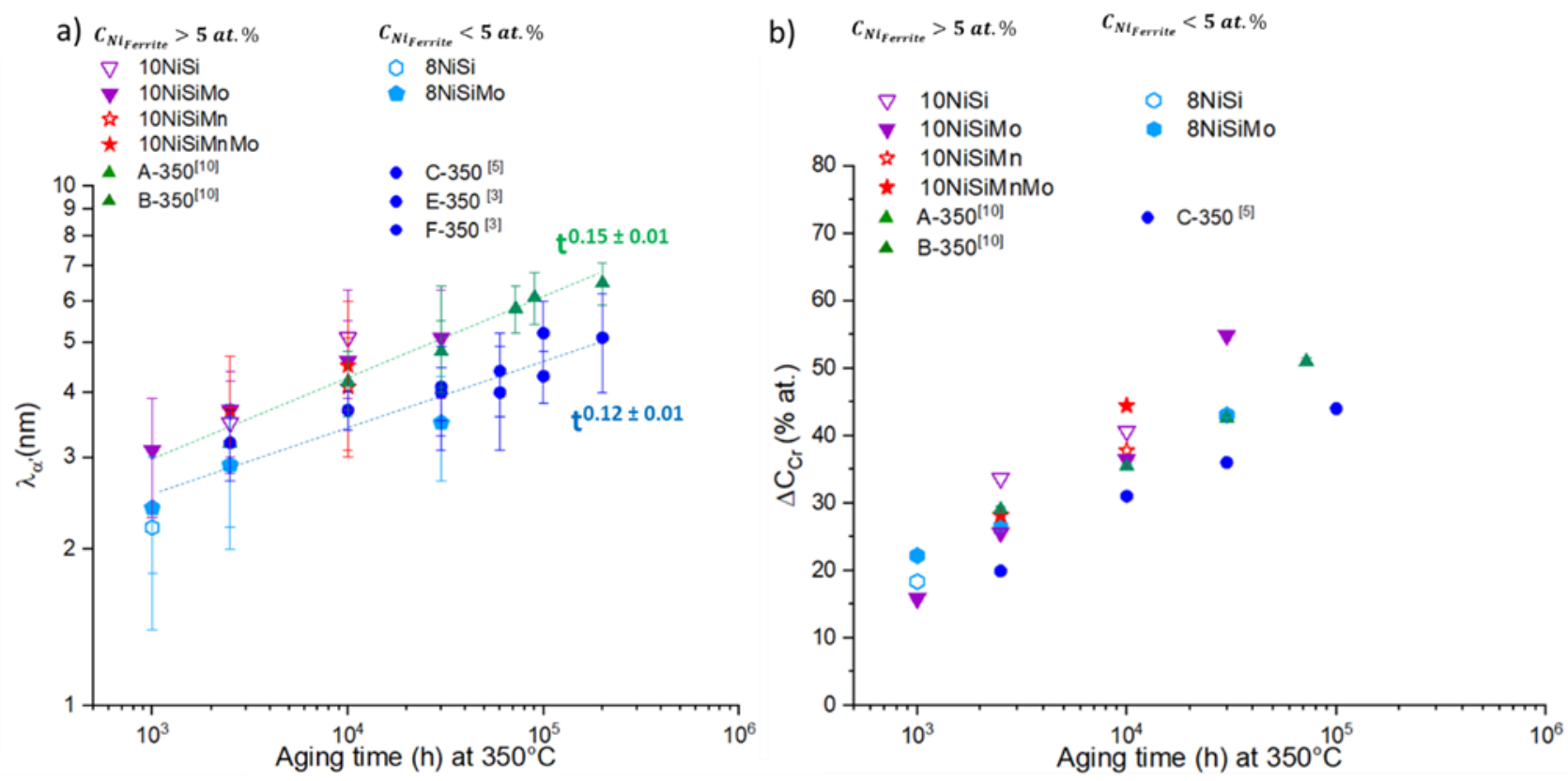

Figure 6: Time evolution of (a) the mean wavelength and (b) the amplitude of $\mathrm{Cr}$ concentration fluctuations of the spinodal decomposition for model alloys aged at $350{ }^{\circ} \mathrm{C}$. The wavelength and amplitude of $8 \mathrm{NiSi}$ and $8 \mathrm{NiSiMo}$ at 2,500 $\mathrm{h}$ are identical, only one point is thus visible on the graph. Blue dash line has been fitted over the wavelength values of model alloys with less than 5 at.\% $\mathrm{Ni}$ in the ferrite. Green dash line has been fitted over the wavelength values of model alloys with more than 5 at. $\% \mathrm{Ni}$ in the ferrite (Color online). 

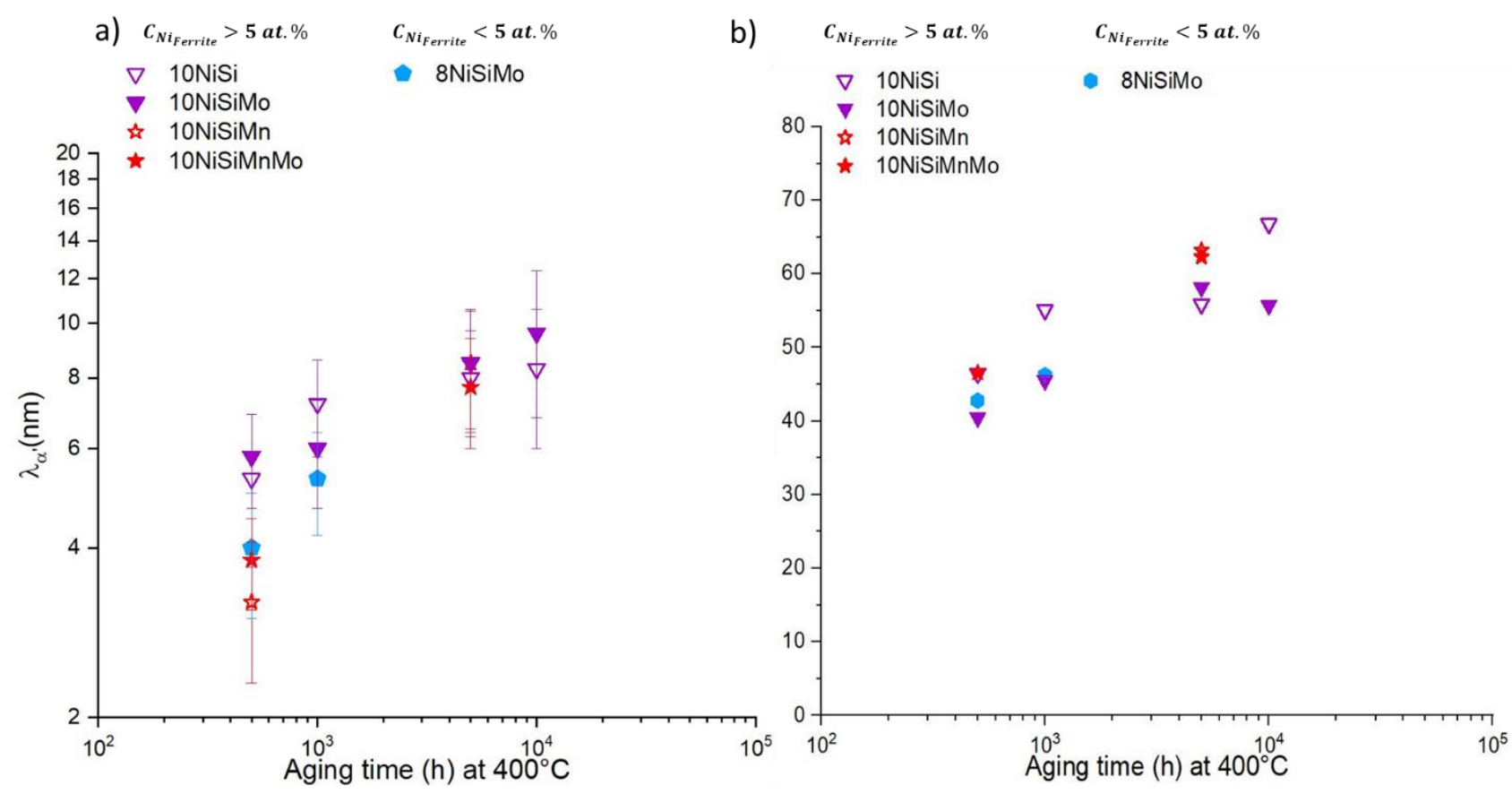

Figure 7: Time evolution of (a) the mean wavelength and (b) amplitude of $\mathrm{Cr}$ concentration fluctuations of the spinodal decomposition for model alloys aged at $400{ }^{\circ} \mathrm{C}$. (Color online)

Except for $10 \mathrm{NiSiMn}$ aged $2,500 \mathrm{~h}$ at $350{ }^{\circ} \mathrm{C}$ for which no spinodal decomposition is observed, the wavelengths of the spinodal decomposition for the different alloys are close. However, a more detailed analysis reveals that the evolution of the wavelength appears slightly slower for alloys with a $\mathrm{Ni}$ content of the ferrite lower than 5 at\% (Figure 6) i.e. the 8Ni series. Indeed, alloys with about 6.5 at\% $\mathrm{Ni}$ in the ferrite (10NiSi, 10NiSiMo, 10NiSiMn and 10NiSiMnMo) have an effective exponent of 0.15 and higher wavelengths while alloys with about 5 at\% $\mathrm{Ni}$ (8NiSi and $8 \mathrm{NiSiMo}$ ) have an effective exponent of 0.12 at $350{ }^{\circ} \mathrm{C}$ and lower wavelengths. Like the austenitic-ferritic stainless steels A-350, B-350 and C-350 [5,10], E-350 and F-350 [3], no evolution of the effective time exponent is observed. The effective exponents only slightly changed when combining the wavelengths of model alloys and industrial steels (from 0.16 to 0.15 for high $\mathrm{Ni}$ content and from 0.09 (considering C-350 for which the value was found to be 0.07 in $[5,10]$ and E-350 and F-350) to 0.12 with low Ni model alloys. At $400{ }^{\circ} \mathrm{C}$, there is no difference between $10 \mathrm{Ni}$ and $8 \mathrm{Ni}$ series.

Regarding the amplitude variation (Figure $6 \mathrm{~b}$ and Figure $7 \mathrm{~b}$ ), no clear tendency appears except the fact that $\mathrm{C}-350$ steel presents the lower amplitude at $350^{\circ} \mathrm{C}$. The amplitude keeps going up even after $10,000 \mathrm{~h}$ at $400{ }^{\circ} \mathrm{C}$. The equilibrium compositions of the $\alpha$ and $\alpha^{\prime}$ phases for the studied ageing range are therefore still not achieved (table S1 and S2). 
$\underline{\text { G-phase particles characterization }}$

\section{G-phase particles at $\alpha / \alpha^{\prime}$ interfaces.}

Figure 8 and Table 4 provide the spatial characteristics and composition of G-phase particles for model alloys with G-phase precipitation at $\alpha / \alpha^{\prime}$ interfaces (10NiSiMn, 10NiSiMo, 10NiSiMnMo) and duplex stainless steels thermally aged at $350{ }^{\circ} \mathrm{C}$, respectively.

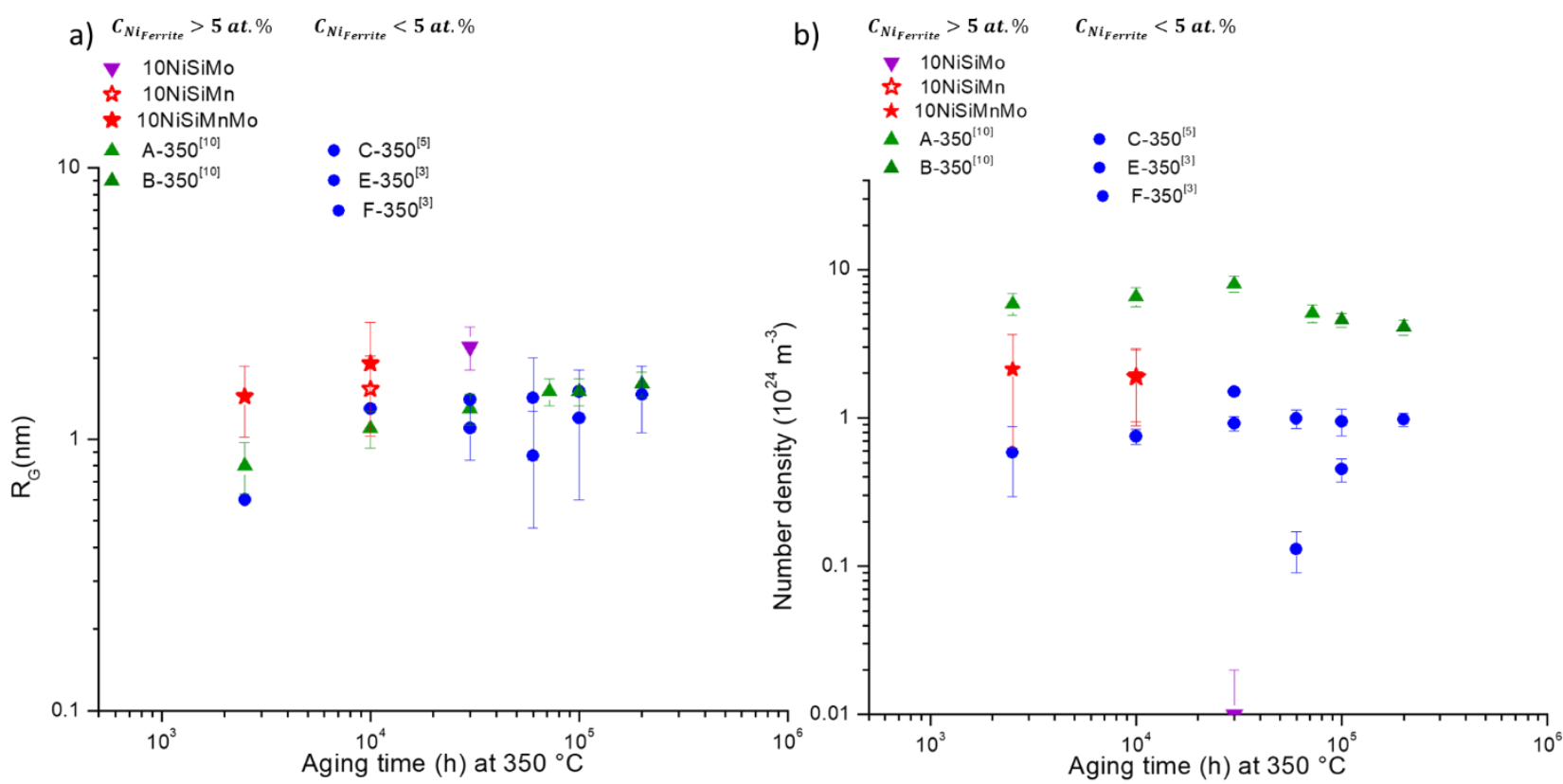

Figure 8: Evolution of G-phase(a) particle radius and (b) number density of particles versus ageing time at $350{ }^{\circ} \mathrm{C}$. The number density of particles of $10 \mathrm{NiSiMn}$ and $10 \mathrm{NiSiMnMo}$ at $10,000 \mathrm{~h}$ are identical, only one point is thus visible on the graph. 
Table 4: G-phase particles composition (at\%) in model alloys and reference industrial alloys at $350{ }^{\circ} \mathrm{C}$ obtained by atom probe tomography. G-forming concentration $=\mathrm{C}_{\mathrm{Ni}}+\mathrm{C}_{\mathrm{Si}}+\mathrm{C}_{\mathrm{Mn}}+\mathrm{C}_{\mathrm{Mo}}$. The uncertainties correspond to three times the standard deviation.

\begin{tabular}{|c|c|c|c|c|c|c|c|c|c|}
\hline Alloy & Thermal ageing & $\mathrm{Ni}$ & $\mathrm{Si}$ & Mn & Mo & $\mathrm{Cr}$ & $\mathrm{Fe}$ & $\mathrm{P}$ & $\begin{array}{c}\text { G- } \\
\text { forming } \\
\text { element } \\
\text { content }\end{array}$ \\
\hline 10NiSiMo & 30,000 h at $350^{\circ} \mathrm{C}$ & $29.3 \pm 1.7$ & $13.7 \pm 1.3$ & $0.1 \pm 0.1$ & $10.7 \pm 1.2$ & $13.1 \pm 1.3$ & $32.9 \pm 1.7$ & / & 53.8 \\
\hline 10NiSiMn & 10,000 h at $350^{\circ} \mathrm{C}$ & $29.0 \pm 0.4$ & $12.4 \pm 0.3$ & $5.7 \pm 0.2$ & 0 & $12.8 \pm 0.3$ & $39.6 \pm 0.4$ & $0.05 \pm 0.02$ & 47.1 \\
\hline 10NiSiMnMo & 2,500 h at $350^{\circ} \mathrm{C}$ & $18.6 \pm 0.4$ & $8.5 \pm 0.3$ & $3.5 \pm 0.2$ & $3.3 \pm 0.2$ & $19.0 \pm 0.4$ & $46.9 \pm 0.4$ & $0.06 \pm 0.02$ & 33.9 \\
\hline 10NiSiMnMo & 10,000 h at $350^{\circ} \mathrm{C}$ & $32.5 \pm 0.5$ & $16.4 \pm 0.4$ & $6.0 \pm 0.3$ & $3.5 \pm 0.2$ & $11.1 \pm 0.3$ & $29.3 \pm 0.5$ & $0.23 \pm 0.03$ & 58.4 \\
\hline \multicolumn{2}{|c|}{$\begin{array}{l}\text { Other model alloys and thermal } \\
\text { conditions }\end{array}$} & \multicolumn{8}{|c|}{ No particles observed at the interfaces $\alpha / \alpha$ ' } \\
\hline A-350 & $\begin{array}{l}10,000 \mathrm{~h} \text { at } \\
350^{\circ} \mathrm{C}\end{array}$ & $20.7 \pm 0.3$ & $9.6 \pm 0.2$ & $3.2 \pm 0.1$ & $3.6 \pm 0.1$ & $17.7 \pm 0.3$ & $45.2 \pm 0.4$ & / & 37.2 \\
\hline $\mathrm{C}-350[10]$ & $\begin{array}{c}10,000 \text { h at } \\
350{ }^{\circ} \mathrm{C}\end{array}$ & $26.5 \pm 1.4$ & $12.5 \pm 1.1$ & $4.4 \pm 0.7$ & $0.2 \pm 0.2$ & $10.6 \pm 1.0$ & $45.2 \pm 1.6$ & l & 43.6 \\
\hline
\end{tabular}

The radius of the G-phase particles at $\alpha / \alpha$ ' interface is similar for all the model alloys but is slightly larger than the one of the G-phase particles of industrial steels. After 10,000 h of ageing at $350{ }^{\circ} \mathrm{C}$, G-phase particles in $10 \mathrm{NiSiMnMo}$ are the richest in G-forming elements. 10NiSiMnMo, which has the same ferrite composition as A-350 steel, has a particle number density 3 times lower and a concentration in G-forming elements 20 at.\% higher. This shows that only considering the G-forming concentration is not enough to understand the behavior of G-phase precipitation. This result has no explanation at the moment.

Table 5 and Table 6 give radius and composition of G-phase particles at $\alpha / \alpha^{\prime}$ interfaces for model alloys at $400{ }^{\circ} \mathrm{C}$ respectively. For some conditions, only few G-phase particles were intercepted in APT volume (Figure 5) so the uncertainties may be important, especially on the number density. For an accurate measurement of number density of G-phase particles, TEM investigation would be necessary. The number density of G-phase particles in the three alloys (10NiSiMn, 10NiSiMo, 10NiSiMnMo) varies between $10^{22}$ and $10^{23} \mathrm{~m}^{-3}$ with the lowest for $10 \mathrm{NiSiMo}$. After $5,000 \mathrm{~h}$ of ageing at $400{ }^{\circ} \mathrm{C}$, particles radius is larger for $10 \mathrm{NiSiMo}$. At this ageing time, particles in 10NiSiMnMo and 10NiSiMn have the same size and contain about 89 at. $\%$ in G-forming elements versus only 66.7 at.\% for $10 \mathrm{NiSiMo.} \mathrm{There} \mathrm{is} \mathrm{no} \mathrm{significant}$ increase in G-forming concentration between 5,000 $\mathrm{h}$ and $10,000 \mathrm{~h}$ of ageing in $10 \mathrm{NiSiMo}$. 
Table 5: G-phase particles radius at $400{ }^{\circ} \mathrm{C}$ obtained by atom probe tomography data analysis.

\begin{tabular}{|c|c|c|c|}
\hline Alloy & Thermal ageing & $\mathrm{R}_{\mathrm{G}}(\mathrm{nm})$ & $\begin{array}{c}\text { Number } \\
\text { density } \\
\left(10^{22} \mathrm{~m}^{-3}\right)\end{array}$ \\
\hline $10 \mathrm{NiSiMo}$ & $5,000 \mathrm{~h}$ at $400{ }^{\circ} \mathrm{C}$ & $4.4 \pm 1.4$ & $2.0 \pm 1.0$ \\
\hline $10 \mathrm{NiSiMo}$ & $10,000 \mathrm{~h}$ at $400{ }^{\circ} \mathrm{C}$ & $5.0 \pm 1.0$ & $2.5 \pm 1.0$ \\
\hline $10 \mathrm{NiSiMn}$ & $5,000 \mathrm{~h}$ at $400{ }^{\circ} \mathrm{C}$ & $3.2 \pm 1.0$ & $16.0 \pm 1.2$ \\
\hline $10 \mathrm{NiSiMnMo}$ & $5,000 \mathrm{~h}$ at $400{ }^{\circ} \mathrm{C}$ & $3.1 \pm 1.1$ & $3.0 \pm 1.0$ \\
\hline
\end{tabular}

Table 6: G-phase particles composition (at\%) as measured at $400{ }^{\circ} \mathrm{C}$. The presence of $\mathrm{Al}$ and $\mathrm{V}$ is also measured at levels below 0.5 at \%

\begin{tabular}{|c|c|c|c|c|c|c|c|c|c|c|}
\hline Alloy & $\begin{array}{l}\text { Thermal } \\
\text { ageing }\end{array}$ & $\mathrm{Ni}$ & $\mathrm{Si}$ & $\mathrm{Mn}$ & Mo & $\mathrm{Cr}$ & $\mathrm{Fe}$ & $\mathrm{P}$ & $\mathrm{C}$ & $\begin{array}{l}\text { G-forming } \\
\text { element } \\
\text { content }\end{array}$ \\
\hline 10NiSiMo & $\begin{array}{c}5,000 \mathrm{~h} \text { at } \\
400{ }^{\circ} \mathrm{C}\end{array}$ & $30.7 \pm 0.6$ & $16.5 \pm 0.5$ & $0.3 \pm 0.1$ & $19.2 \pm 0.5$ & $16.1 \pm 0.5$ & $14.9 \pm 0.5$ & $0.3 \pm 0.1$ & $1.33 \pm 0.16$ & 66.7 \\
\hline 10NiSiMo & $\begin{array}{c}10,000 \mathrm{~h} \text { at } \\
400{ }^{\circ} \mathrm{C}\end{array}$ & $29.5 \pm 1.1$ & $17.0 \pm 0.9$ & $0.1 \pm 0.1$ & $21.3 \pm 0.9$ & $15.7 \pm 0.9$ & $12.6 \pm 0.8$ & $0.2 \pm 0.1$ & $1.63 \pm 0.31$ & 67.9 \\
\hline 10NiSiMn & $\begin{array}{c}5,000 \mathrm{~h} \text { at } \\
400{ }^{\circ} \mathrm{C}\end{array}$ & $51.5 \pm 0.4$ & $22.6 \pm 0.4$ & $15.3 \pm 0.3$ & I & $2.6 \pm 0.1$ & $7.8 \pm 0.2$ & $0.1 \pm 0.1$ & $0.02 \pm 0.01$ & 89.4 \\
\hline 10NiSiMnMo & $\begin{array}{c}5,000 \mathrm{~h} \text { at } \\
400{ }^{\circ} \mathrm{C}\end{array}$ & $45.0 \pm 0.6$ & $27.9 \pm 0.5$ & $10.7 \pm 0.4$ & $6.2 \pm 0.3$ & $6.4 \pm 0.3$ & $9.3 \pm 0.3$ & $0.2 \pm 0.1$ & $0.28 \pm 0.06$ & 89.8 \\
\hline $\begin{array}{l}\text { Other models } \\
\text { alloys and } \\
\text { thermal } \\
\text { conditions }\end{array}$ & $\begin{array}{c}500 \mathrm{~h} \text { to } \\
5,000 \mathrm{~h} \text { at } \\
400{ }^{\circ} \mathrm{C}\end{array}$ & \multicolumn{9}{|c|}{ No particles observed at the interfaces $\alpha / \alpha$} \\
\hline
\end{tabular}

\section{G-phase particles along dislocation lines}

Particles along dislocation lines were observed in 8NiSiMo, 8NiSi [34], 10NiSiMo and 10NiSiMnMo. The composition and radius of these particles are shown in Table 7. G-forming content varies from 45.6 at.\% to 82.1 at.\%. After the same ageing treatment, G-phase particles at dislocation lines are richer in G-forming elements than particles at $\alpha / \alpha^{\prime}$ interfaces. 
Table 7: Composition (at\%) and radius of G-phase particles at dislocation line for different model alloys and thermal ageing.

\begin{tabular}{|c|c|c|c|c|c|c|c|c|c|c|}
\hline Alloys & Ageing & $\mathrm{Ni}$ & $\mathrm{Si}$ & $\mathrm{Mn}$ & $\mathrm{Mo}$ & $\mathrm{Cr}$ & $\mathrm{Fe}$ & $\mathrm{P}$ & $\begin{array}{c}\text { Rg (nm) } \\
\text { (n-forming } \\
\text { element } \\
\text { content }\end{array}$ \\
\hline $8 \mathrm{NiSi}$ & 2,500 at $350^{\circ} \mathrm{C}$ & $39.2 \pm 3.2$ & $19.1 \pm 2.6$ & Trace & Trace & $15.2 \pm 2.4$ & $26.5 \pm 2.9$ & $/$ & 2.8 & 58.5 \\
\hline $8 \mathrm{NiSiMo}$ & 2,500 at $350{ }^{\circ} \mathrm{C}$ & $25.7 \pm 3.2$ & $13.1 \pm 2.5$ & Trace & $6.8 \pm 1.8$ & $10.3 \pm 2.2$ & $44.0 \pm 3.6$ & $0.3 \pm 0.2$ & $1.5 \pm 0.4$ & 45.6 \\
\hline $10 \mathrm{NiSiMo}$ & $10,000 \mathrm{~h}$ at $350{ }^{\circ} \mathrm{C}$ & $36.1 \pm 2.9$ & $18.9 \pm 2.4$ & $0.2 \pm 0.2$ & $12.9 \pm 2.0$ & $15.1 \pm 2.2$ & $16.6 \pm 2.3$ & $/$ & $3.1 \pm 0.4$ & 67.9 \\
\hline $10 \mathrm{NiSiMo}$ & $500 \mathrm{~h}$ at $400{ }^{\circ} \mathrm{C}$ & $32.7 \pm 2.4$ & $12.7 \pm 1.7$ & $0.1 \pm 0.2$ & $15.2 \pm 1.8$ & $16.4 \pm 1.9$ & $21.5 \pm 2.1$ & $0.2 \pm 0.2$ & $4.9 \pm 1.8$ & 60.7 \\
\hline $10 \mathrm{NiSiMnMo}$ & $500 \mathrm{~h}$ at $400{ }^{\circ} \mathrm{C}$ & $48.2 \pm 2.4$ & $19.9 \pm 1.9$ & $12.2 \pm 1.5$ & $1.8 \pm 0.6$ & $5.5 \pm 1.1$ & $12.2 \pm 1.5$ & $/$ & $3.7 \pm 1.0$ & 82.1 \\
\hline
\end{tabular}

\section{Discussion}

\section{$\underline{\text { Spinodal decomposition: }}$}

Danoix et al. and Pareige et al. [5,10] measured an effective time exponent of spinodal decomposition kinetics equals to 0.16 considering several Mo-bearing steels thermally aged up to 20 years at $350{ }^{\circ} \mathrm{C}$ and equal to 0.09 for a Mo-free steel thermally aged up to 10 years at $350{ }^{\circ} \mathrm{C}$. This difference could be explained by the difference in $\mathrm{Ni}$ and/or Mo content or by a synergetic effect between Ni and Mo but also by the fact that only one Mo-free alloys has been investigated.

Taking into account results obtained in the model alloys and in other Mo-free steels [3] (thus improving statistics), the time exponent slightly change to 0.15 for Mo-bearing and 0.12 for Mo-free alloys. Improving statistics by considering different alloys of the same familly decreases significantly the observed difference in time exponent. However, this does not change the fact that the values of the wavelengths are larger in Mo-bearing steels (Figure 6). The data obtained in the model alloys (Figure 6) show that what distinguishes the alloys having a higher or a lower effective time exponent is only the $\mathrm{Ni}$ content. Indeed, the low exponent family (blue dots) contains alloys with and without Mo or Mn (8NiSi and $8 \mathrm{NiSiMo}$ for example). Similarly, the family with the highest time exponent is also made of alloys with or without Mo and Mn (10NiSi and 10NiSiMnMo for example). This clearly shows that whatever the concentration in Mo or Mn, the time exponent remains unchanged. In good agreement with literature [2,12-14], results show that $\mathrm{Ni}$ accelerates spinodal decomposition and neither Mo nor Mn have any significant influence on the spinodal kinetics for the concentrations investigated here. This also 
agrees with the conclusions of Solomon and Levinson [2] on the influence of Mo and Mn on the spinodal decomposition. Mn/Mo and Ni/Mo couplings do not cause any additional effect on the spinodal decomposition kinetics. Our work shows that $\mathrm{Ni}$ is at the origin of the difference in kinetics between Mo-bearing and Mo-free steels.

\section{G-phase precipitation:}

G-phase particles are observed in the $10 \mathrm{NiSi}$ series only when 0.4 wt. $\% \mathrm{Mn}$ and/or 2.6 wt.\% Mo are added. Ni and Si are not enough for G-phase particles to precipitate at $\alpha / \alpha$ ' interfaces for the considered ageing time. Similarly, no G-phase particles are observed in $8 \mathrm{NiSi}$. This is in good agreement with the thermodynamic calculations performed with the open source MatCalc mc_fe database updated by Jacob et al. [35] as shown in Figure 9. G-phase is not expected in alloys without Mo and/or Mn at $350{ }^{\circ} \mathrm{C}$ and $400{ }^{\circ} \mathrm{C}$.

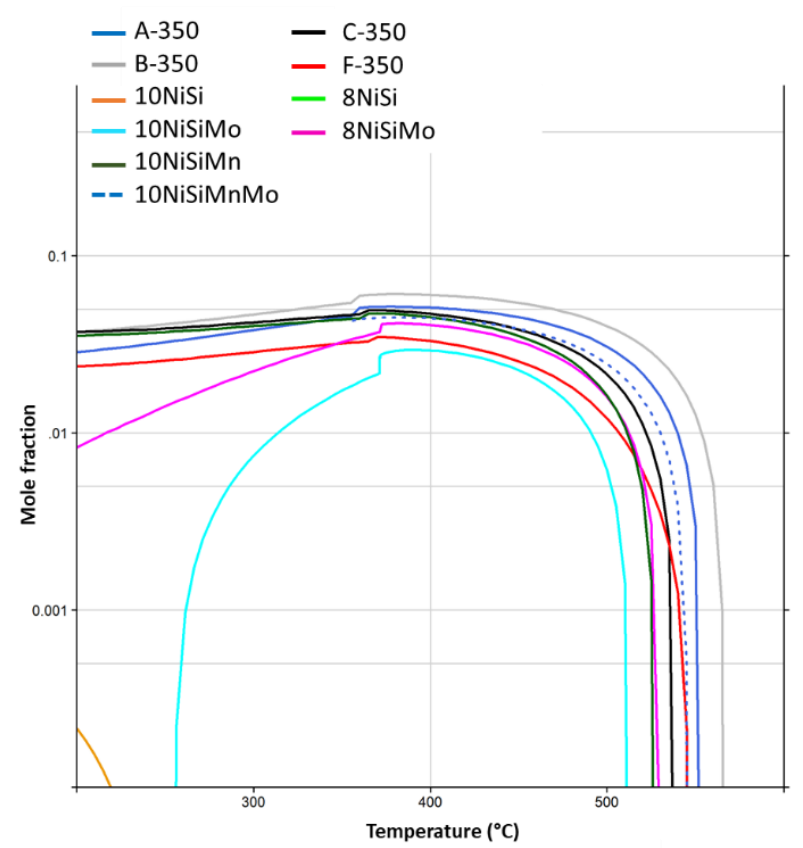

Figure 9: Calculated equilibrium phase fraction of G-phase as function of temperature using the updated MatCalc mc_fe database [35].

After $2,500 \mathrm{~h}$ at $350{ }^{\circ} \mathrm{C}$, no G-phase precipitation is observed in $10 \mathrm{NiSiMn}$ whereas G-phase particles are observed after $10,000 \mathrm{~h}$. This kinetic delay is very likely due to the absence of spinodal decomposition. Indeed, development of spinodal decomposition has been shown to induce the formation of G-phase particles owing to the appearance of a cross flow of the Gforming elements at the $\alpha / \alpha^{\prime}$ interfaces [31,33]. One could also consider that the kinetic delay is partly due to the absence of Mo as G-phase particles are observed after 2,500h in $10 \mathrm{NiSiMnMo.} \mathrm{But} \mathrm{in} \mathrm{the} \mathrm{latter} \mathrm{case} \mathrm{spinodal} \mathrm{decomposition} \mathrm{is} \mathrm{well} \mathrm{visible} \mathrm{and} \mathrm{could} \mathrm{explain}$ 
the formation of the G-phase particles at $\alpha / \alpha^{\prime}$ interface. Comparison of the $3 \mathrm{D}$ images of 10NiSiMn and 10NiSiMo alloys in Figure 2, clearly evidences the major role of Mn on the Gphase precipitation: whereas G-phase particles are only observed at dislocation lines in $10 \mathrm{NiSiMo}$, a dense precipitation at $\alpha / \alpha^{\prime}$ interfaces is observed in $10 \mathrm{NiSiMn}$. In both cases, spinodal decomposition has similar characteristics. In $8 \mathrm{NiSi}$ series which do not contain $\mathrm{Mn}$, no G-phase particles at $\alpha / \alpha^{\prime}$ interface have been observed whatever the Mo content. Conversely, G-phase is observed in Mo-free steels which contain Mn but no Mo. These results show that (i) Mn enables the nucleation of G-phase particles at $\alpha / \alpha^{\prime}$ interfaces and (ii) Mo alone does not enable the nucleation of G-phase particles at $\alpha / \alpha^{\prime}$ interface for both high and low Ni content alloys. Nevertheless, it must be emphasized that G-phase particles were observed along dislocation lines in $10 \mathrm{NiSiMo}$ and $8 \mathrm{NiSiMo}$. Mo play a role for the heterogeneous precipitation of G-phase at dislocation lines. G-phase nucleation at $\alpha / \alpha^{\prime}$ interface in industrial steels is thus very likely favored by the presence of Mn. Of course, when G-phase particles are formed, a higher concentration in Mo or $\mathrm{Ni}$ in the alloys lead to a higher equilibrium volume fraction of G-phase precipitates (as the G-forming concentration is increased) which explains why a higher number density of particles is measured in Mo-bearing steels than in Mo-free steels.

A-350 and 10NiSiMnMo alloys have similar ferrite composition with only a slight difference in Ni concentration. However, the kinetics of G-phase particles is different: A-350 industrial steel contains a higher number density of slightly smaller particles containing a lower concentration in G-forming elements. This cannot be explained by the difference in Ni content as the highest number density is observed for the industrial alloy with the lowest $\mathrm{Ni}$ concentration. Composition of the ferrite of steels is thus not the only factor influencing the precipitation of G-phase particles at the $\alpha / \alpha^{\prime}$ interfaces. This point needs further investigations to be clarified.

In contrast to the precipitation at the $\alpha / \alpha^{\prime}$ interfaces, the presence of $\mathrm{Ni}$ and $\mathrm{Si}$ alone allows the precipitation of the G-phase particles along the dislocation lines [34]. Hamaoka et al. [36] also observed this type of particles in an industrial Mo-bearing steel (like alloy A-350 and B-350). It is not possible to estimate the number density of these particles by atom probe tomography, TEM investigation is more adapted. 


\section{Conclusion}

Model alloys with different $\mathrm{Ni}$, Mo and Mn concentrations have been studied by atom probe tomography to determine the effect of these elements on the decomposition of ferrite by spinodal decomposition and G-phase precipitation:

Regarding spinodal decomposition:

- The kinetics of the spinodal decomposition appears to be influenced only by $\mathrm{Ni}$ concentration and not by Mn or Mo concentration (in the studied concentration range). $\mathrm{Ni}$ accelerates the kinetics.

- The Mn/Mo and Ni/Mo couplings do not seem to have any additional effect on the kinetics of spinodal decomposition.

Regarding G-phase precipitation:

- Mn is a critical element. Without Mn, no G-particles are observed at the $\alpha / \alpha$ ' interfaces in the temperature and time ranges investigated. Mo alone does not lead to nucleation of G-phase particles at $\alpha / \alpha^{\prime}$ interface but enables precipitation of G-phase particles at dislocation lines.

- The presence of both Mo and Mn significantly facilitates the precipitation kinetics of the G-phase (no kinetic delay observed). It was found that adding only $0.4 \mathrm{wt} \% \mathrm{Mn}$ has more impact on the precipitation kinetics than adding $2.6 \mathrm{wt} \%$ Mo.

- This study also reveals that the composition of the ferrite of steels is not the only factor influencing the precipitation of G-phase particles at the $\alpha / \alpha^{\prime}$ interfaces.

\section{Acknowledgements}

This work contributes to the research program of the EDF-CNRS joint laboratory EM2VM (Study and Modeling of the Microstructure for Ageing of Materials). This work was carried out owing to experimental GENESIS platform. GENESIS is supported by the Région HauteNormandie, the Métropole Rouen Normandie, the CNRS via LABEX EMC and the French Natonal Research Agency as a part of the program "Investissements d'avenir" with the reference ANR-11-EQPX-0020. 


\section{References.}

[1] P. Auger, F. Danoix, A. Menand, S. Bonnet, J. Bourgoin, M. Guttmann, Atom probe and transmission electron microscopy study of aging of cast duplex stainless steels, Mater. Sci. Technol. 6 (1990) 301-313. https://doi.org/10.1179/mst.1990.6.3.301.

[2] H.D. Solomon, L.M. Levinson, Mössbauer effect study of ' $475^{\circ} \mathrm{C}$ embrittlement' of duplex and ferritic stainless steels, Acta Metall. 26 (1978) 429-442. https://doi.org/10.1016/00016160(78)90169-4.

[3] R. Badyka, G. Monnet, S. Saillet, C. Domain, C. Pareige, Quantification of hardening contribution of G-Phase precipitation and spinodal decomposition in aged duplex stainless steel: APT analysis and micro-hardness measurements, J. Nucl. Mater. 514 (2019) 266275. https://doi.org/10.1016/j.jnucmat.2018.12.002.

[4] F. Danoix, P. Auger, Atom Probe Studies of the Fe-Cr System and Stainless Steels Aged at Intermediate Temperature: A Review, Mater. Charact. 44 (2000) 177-201. https://doi.org/10.1016/S1044-5803(99)00048-0.

[5] C. Pareige, J. Emo, S. Saillet, C. Domain, P. Pareige, Kinetics of G-phase precipitation and spinodal decomposition in very long aged ferrite of a Mo-free duplex stainless steel, J. Nucl. Mater. 465 (2015) 383-389. https://doi.org/10.1016/j.jnucmat.2015.06.017.

[6] A. Trautwein, Influence of long time aging of CF8 and CF8M cast steel at temperatures between 300 and $500^{\circ} \mathrm{C}$ on the impact toughness and the structure properties, AFS Int. Cast Met. J. 6 (1981) 43-54.

[7] S. Bonnet, J. Bourgoin, J. Champredonde, D. Guttmann, M. Guttmann, Relationship between evolution of mechanical properties of various cast duplex stainless steels and metallurgical and aging parameters: outline of current EDF programmes, in: Mater. Sci. Technol., 1990: pp. 221-229.

[8] H.M. Chung, T.R. Leax, Embrittlement of laboratory and reactor aged CF3,CF8, and CF8M duplex stainless steels, Mater. Sci. Technol. 6 (1990) 249-262. https://doi.org/10.1179/mst.1990.6.3.249.

[9] F. Danoix, P. Auger, D. Blavette, Hardening of Aged Duplex Stainless Steels by Spinodal Decomposition, Microsc. Microanal. $10 \quad$ (2004) 349-354. https://doi.org/10.1017/S1431927604040516.

[10] C. Pareige, S. Novy, S. Saillet, P. Pareige, Study of phase transformation and mechanical properties evolution of duplex stainless steels after long term thermal ageing (>20 years), J. Nucl. Mater. $411 \quad$ (2011) 90-96. https://doi.org/10.1016/j.jnucmat.2011.01.036.

[11] H.M. Chung, Aging and life prediction of cast duplex stainless steel components, Int. J. Press. Vessels Pip. 50 (1992) 179-213. https://doi.org/10.1016/0308-0161(92)90037-G.

[12] J.E. Brown, G.D.W. Smith, Atom probe studies of spinodal processes in duplex stainless steels and single- and dual-phase Fe-Cr-Ni alloys, Surf. Sci. 246 (1991) 285-291. https://doi.org/10.1016/0039-6028(91)90428-U.

[13] B. Trindade, R. Vilar, Influence of nickel on $475^{\circ} \mathrm{C}$ embrittlement of $\mathrm{Fe}-\mathrm{Cr}-\mathrm{Ni}$ alloys: Mössbauer effect study, Hyperfine Interact. 66 (1991) 351-358. https://doi.org/10.1007/BF02395885.

[14] P. Hedström, F. Huyan, J. Zhou, S. Wessman, M. Thuvander, J. Odqvist, The $475{ }^{\circ} \mathrm{C}$ embrittlement in $\mathrm{Fe}-20 \mathrm{Cr}$ and $\mathrm{Fe}-20 \mathrm{Cr}-\mathrm{X}(\mathrm{X}=\mathrm{Ni}, \mathrm{Cu}, \mathrm{Mn})$ alloys studied by mechanical testing and atom probe tomography, Mater. Sci. Eng. A. 574 (2013) 123-129. https://doi.org/10.1016/j.msea.2013.03.016.

[15] M. Courtnall, F.B. Pickering, The effect of alloying on $485^{\circ} \mathrm{C}$ embrittlement, Met. Sci. 10 (1976) 273-276. https://doi.org/10.1179/030634576790432353. 
[16] J.J. Shiao, C.H. Tsai, J.J. Kai, J.H. Huang, Aging embrittlement and lattice image analysis in a Fe-Cr-Ni duplex stainless steel aged at $400^{\circ} \mathrm{C}$, J. Nucl. Mater. 217 (1994) 269278. https://doi.org/10.1016/0022-3115(94)90376-X.

[17] M.K. Miller, J. Bentley, APFIM and AEM investigation of CF8 and CF8M primary coolant pipe steels, Mater. Sci. Technol. 6 (1990) 285.

[18] F. Danoix, D. Blavette, P. Auger, An atom-probe investigation of some correlated phase transformation in Cr,Ni,Mo containting supersatured ferrite, Surf. Sci. 266 (1992).

[19] T. Hamaoka, T.J. Konno, T. Sawabe, K. Nishida, K. Dohi, Effects of molybdenum on precipitation behaviours in aged cast stainless steels, Philos. Mag. 0 (2016) 1-19. https://doi.org/10.1080/14786435.2016.1205231.

[20] S. Bonnet, J. Bourgoin, J. Champredonde, D. Guttmann, M. Guttmann, Relationship between evolution of mechanical properties of various cast duplex stainless steels and metallurgical and aging parameters: outline of current EDF programmes, in: Mater. Sci. Technol., 1990: pp. 221-229.

[21] B. Gault, M. P.Moody, Atom Probe Microscopy, Springer, Springer, n.d.

[22] W. Lefebvre, F. Vurpillot, X. Sauvage, Atom Probe Tomography: Put Theory Into Practice, Academic Press, 2016.

[23] D.J. Larson, TyJ. Prosa, R.M. Ulfig, B.P. Geiser, T.F. Kelly, Local electrode atom probe tomography. A User's Guide, Springer, 2013.

[24] M.G. Hetherington, M.K. Miller, Some aspects of the measurement of composition in the atom probe, J. Phys. Colloq. 50 (1989) C8-535-C8-540. https://doi.org/10.1051/jphyscol:1989892.

[25] J. Zhou, J. Odqvist, M. Thuvander, P. Hedström, Quantitative evaluation of spinodal decomposition in $\mathrm{Fe}-\mathrm{Cr}$ by atom probe tomography and radial distribution function analysis, Microsc. Microanal. Off. J. Microsc. Soc. Am. Microbeam Anal. Soc. Microsc. Soc. Can. 19 (2013) 665-675. https://doi.org/10.1017/S1431927613000470.

[26] J.M. Hyde, G. DaCosta, C. Hatzoglou, H. Weekes, B. Radiguet, P.D. Styman, F. Vurpillot, C. Pareige, A. Etienne, G. Bonny, N. Castin, L. Malerba, P. Pareige, Analysis of Radiation Damage in Light Water Reactors: Comparison of Cluster Analysis Methods for the Analysis of Atom Probe Data, Microsc. Microanal. 23 (2017) 366-375. https://doi.org/10.1017/S1431927616012678.

[27] J.M. Hyde, G. DaCosta, C. Hatzoglou, H. Weekes, B. Radiguet, P.D. Styman, F. Vurpillot, C. Pareige, A. Etienne, G. Bonny, N. Castin, L. Malerba, P. Pareige, Analysis of Radiation Damage in Light Water Reactors: Comparison of Cluster Analysis Methods for the Analysis of Atom Probe Data, Microsc. Microanal. 23 (2017) 366-375. https://doi.org/10.1017/S1431927616012678.

[28] F. Vurpillot, A. Bostel, D. Blavette, Trajectory overlaps and local magnification in three-dimensional atom probe, Appl. Phys. Lett. 76 (2000) 3127-3129. https://doi.org/10.1063/1.126545.

[29] D. Blavette, F. Vurpillot, P. Pareige, A. Menand, A model accounting for spatial overlaps in 3D atom-probe microscopy, Ultramicroscopy. 89 (2001) 145-153. https://doi.org/10.1016/S0304-3991(01)00120-6.

[30] C. Hatzoglou, B. Radiguet, G. Da Costa, P. Pareige, M. Roussel, M. HernandezMayoral, C. Pareige, Quantification of APT physical limitations on chemical composition of precipitates in $\mathrm{Fe}-\mathrm{Cr}$ alloys, J. Nucl. Mater. 522 (2019) 64-73. https://doi.org/10.1016/j.jnucmat.2019.05.022.

[31] A. Mateo, L. Llanes, M. Anglada, A. Redjaimia, G. Metauer, Characterization of the intermetallic G-phase in an AISI 329 duplex stainless steel, J. Mater. Sci. 32 (1997) 45334540. https://doi.org/10.1023/A:1018669217124. 
[32] J. Emo, C. Pareige, S. Saillet, C. Domain, P. Pareige, Kinetics of secondary phase precipitation during spinodal decomposition in duplex stainless steels: A kinetic Monte Carlo model - Comparison with atom probe tomography experiments, J. Nucl. Mater. 451 (2014) 361-365. https://doi.org/10.1016/j.jnucmat.2014.04.025.

[33] F. Danoix, P. Auger, S. Chambreland, D. Blavette, A 3D study of G-phase precipitation in spinodally decomposed $\alpha$-ferrite by tomographic atom-probe analysis, Microsc. Microanal. Microstruct. $\quad 5 \quad$ (1994) 121-132. https://doi.org/10.1051/mmm:0199400502012100.

[34] J. Emo, Etude expérimentale et par simulation Monte Carlo des transformations de phase dans la ferrite des aciers austéno-ferritiques et de leurs alliages modèles, Rouen, 2014.

[35] A. Jacob, C. Domain, G. Adjanor, P. Todeschini, E. Povoden-Karadeniz, Thermodynamic modeling of G-phase and assessment of phase stabilities in reactor pressure vessel steels and cast duplex stainless steels, J. Nucl. Mater. 533 (2020) 152091. https://doi.org/10.1016/j.jnucmat.2020.152091.

[36] T. Hamaoka, A. Nomoto, K. Nishida, K. Dohi, N. Soneda, Effects of aging temperature on G-phase precipitation and ferrite-phase decomposition in duplex stainless steel, Philos. Mag. 92 (2012) 4354-4375. https://doi.org/10.1080/14786435.2012.707340. 